\title{
Comparative of Maximum Power Point Tracking Solar Photovoltaic Fed Brushless DC Motor
}

\author{
Ahmed Mohammed Abdul Hussain \\ Electrical Engineering Department \\ University of Baghdad
}

\author{
Hanan Mikhael D. Habbi \\ Electrical Engineering Department \\ University of Baghdad
}

\begin{abstract}
This paper proposes a simple, cost effective and efficient brushless DC (BLDC) motor drive for solar photovoltaic (SPV) array fed water pumping system. The importance of using a maximum power point tracking (MPPT) algorithm is demonstrated to ensure that a PV system provides the most energy possible. Two different maximum power point tracking (MPPT) algorithms are introduced. A boost converter is used in order to extract the maximum available power from the SPV. An appropriate control of boost converter through the Perturb \& Observe maximum power point tracking (POMPPT) algorithm offers soft starting of the BLDC motor. Increment conductance is used and compared with the PO MPPT. The speed control of BLDC motor is performed by PWM (Pulse Width Modulation) control of the voltage source inverter (VSI) using DC link voltage regulator. A Matlab/ Simulink models of the solar panel, dc to dc boost converter, and control algorithms are validated.
\end{abstract}

\section{Keywords}

Solar PV, maximum power point tracking (MPPT) algorithms, BLDC motor, DC -DC boost converter.

\section{INTRODUCTION}

The water pumping has become the most attractive application of solar photovoltaic (SPV) energy particularly in the remote rural areas where power transmission is either almost impossible or uneconomical if possible. In general, a DC-DC converter is employed for maximum power point tracking (MPPT) of a SPV. A DC-DC Boost converter is used in for a permanent magnet brushless DC (BLDC) motor driven centrifugal pump. A DC-DC boost converter is utilized in MPPT of the SPV. The reasons behind opting this converter are its inherent properties of minimum possible switching stress, high conversion efficiency because of less number of components. The merits of both BLDC motor and Boost converter can contribute to develop a SPV array fed water pumping system possessing a potential of operating satisfactorily under dynamically changing atmospheric conditions. The BLDC motor has high reliability, high efficiency, improved cooling, low noise and requires practically no maintenance, since the BLDC motor speed is commanded by pulse width modulation (PWM) of VSI using a DC link voltage regulator. The centrifugal pump connected to the shaft of the motor operates the pump at constant speed to deliver the desired throughput for different irradiance levels of the SPV. The experimental analysis of impact of MPPT methods on energy efficiency for photovoltaic power systems is presented [1]. The modified incremental conductance MPPT algorithm to mitigate inaccurate responses under fastchanging solar irradiation level is introduced [2-3]. References [4-5] discuss and demonstrate a comparison of maximum power point tracking techniques for photovoltaic power systems.

A relationship between the dc power produced by PV array and the solar radiation has been investigated in [6]. It is showed that the power delivered by the PV array under the MPPT algorithm is linear with the radiation and it depends on temperature, ect. The steady state and transient conditions have been solved by using current based MPPT [7].

In this paper, the importance of using a maximum power point tracking (MPPT) algorithm is demonstrated to ensure that a PV system provides the most energy possible. Two different MPPT algorithms are introduced. A Matlab/ Simulink models of the solar panel, $\mathrm{dc}$ to $\mathrm{dc}$ boost converter, and control algorithms are validated.

\section{MAXIMUM POWER POINT \\ TRACKING ALGORITHM}

In order to investigate the mismatching between the operating characteristics of the load and the PV array, that's point represents the intersection of the IV curves of the PV array and the load. Therefore, this substantial problem can be solved avoiding the direct connection of PV array to the load. A maximum power point tracking is considered. MPPT keeps the PV array point at the maximum. Several MPP techniques have been utilized by many researchers such as (Perturb and Observe (P\&O), Incremental Conductance (IC) and Fuzzy Logic [8]). However, the two most commonly used are P\&O and IC among the other techniques because of its simple structure and ease of implementation. The PV array characteristics and the detail of its modeling are discussed in Ref [9]. Consequently, the important values of the PV array are the open voltage, the short circuit current and the MPP to get the PV array characteristics. The specification of the PV is given in Table 1.

Table 1. PV characteristics

2.1 Perturb and observe (P\&O) algorithm

\begin{tabular}{|l|l|l|}
\hline Parameters & Value & Unit \\
\hline Maximum power (Pmax) & 300 & $\mathrm{~W}$ \\
\hline Maximum power voltage (Vmax) & 36.48 & $\mathrm{~V}$ \\
\hline Maximum power current (Imax) & 7.95 & $\mathrm{~A}$ \\
\hline Short circuit current (Isc) & 8.9 & $\mathrm{~A}$ \\
\hline Open circuit voltage (Voc) & 45.29 & $\mathrm{~V}$ \\
\hline Series resistance $($ Rs $)$ & 0.4 & $\Omega$ \\
\hline Shunt resistance $($ Rsh $)$ & 68.4 & $\Omega$ \\
\hline
\end{tabular}

It is based on the concept that on the power-voltage curve, the change in the PV array output power is equal to zero $(\Delta \mathrm{Ppv}$ 
$=0$ ) on the top of the curve as illustrated in Fig. 1. The P\&O technique compares the power of the previous step and the new step so that it increases or decreases the voltage or current [10-11]. Operating on the left of the MPP, it is noticeable that incrementing (decrementing) the voltage allows to increase (decrease) the power and decrease (increase) the power when on the right of the MPP. The perturbation is kept the same to reach the MPP when there is an increase in power and vice-versa. $\mathrm{P} \& \mathrm{O}$ has a good behavior when the irradiance does not change quickly with time. However, the power oscillates around the MPP in steady state operation and it fails with variations of temperature and irradiance. Considering a small perturbation size to maintain a small power variation. The basic flow chart of $\mathrm{P} \& \mathrm{O}$ algorithm is shown in Fig.2.

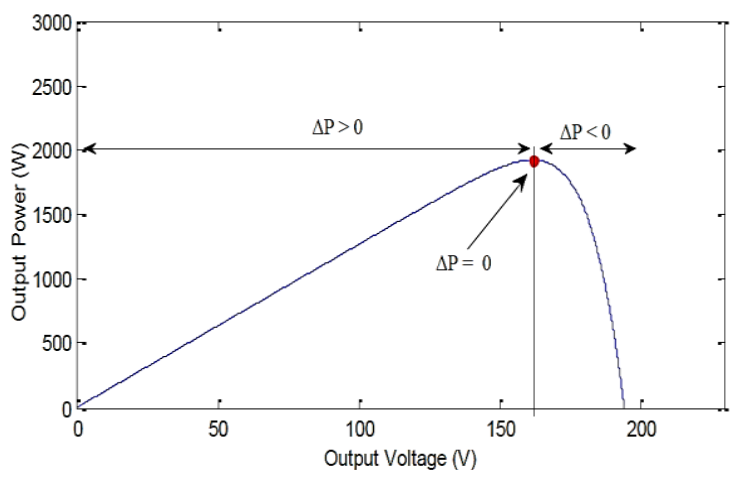

Fig 1: Sign of the dP/dV at different positions on the power characteristic

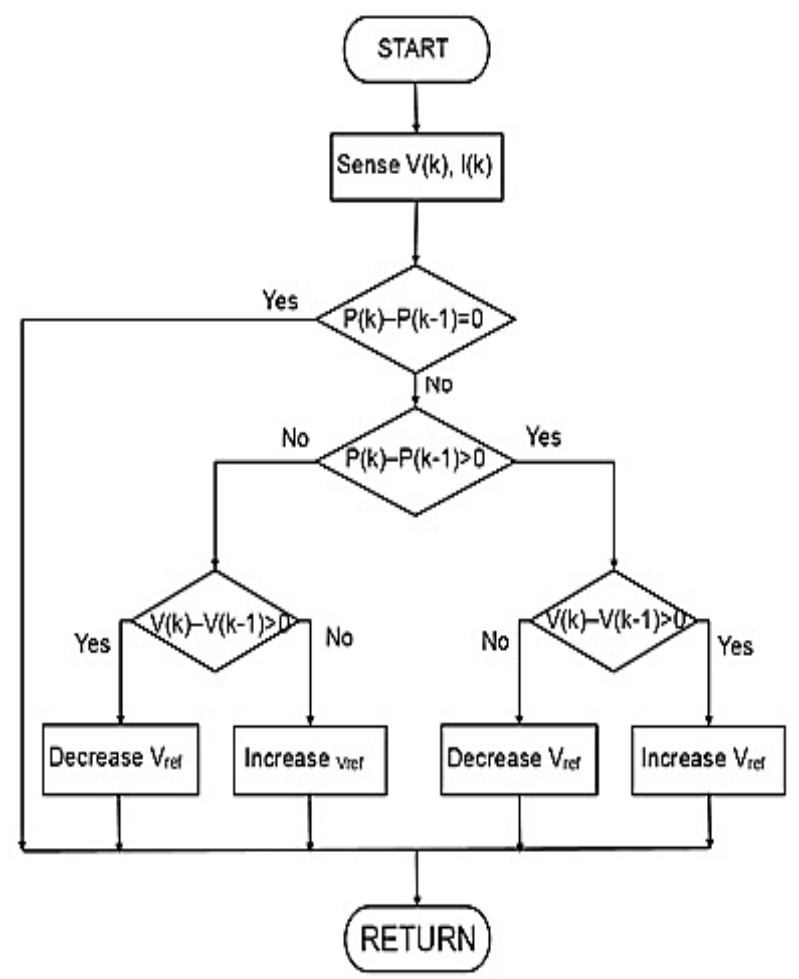

Fig 2: Flowchart of the P\&O algorithm.
This algorithm is developed to set up the duty ratio of the PWM generator that it controls the boost DC - DC converter (section 3).

\subsection{Incremental conductance (INC) algorithm}

The INC algorithm is based on the fact that, the derivative of $\mathrm{PV}$ array output power with respect to its output voltage is zero $(\mathrm{dP} / \mathrm{dV}=0)$ at the MPP and at any irradiation and temperature level. It is negative on the right of MPP and positive on the left of the MPP as shown in Fig 3. The Flowchart of the incremental conductance algorithm is shown in Fig 4.

$$
\begin{aligned}
& \Delta V / \Delta P=0(\Delta \mathrm{I} / \Delta P=0) \text { at the MPP } \\
& \Delta V / \Delta P>0(\Delta \mathrm{I} / \Delta P<0) \text { on the left } \\
& \Delta V / \Delta P<0(\Delta \mathrm{I} / \Delta P>0) \text { on the right }
\end{aligned}
$$

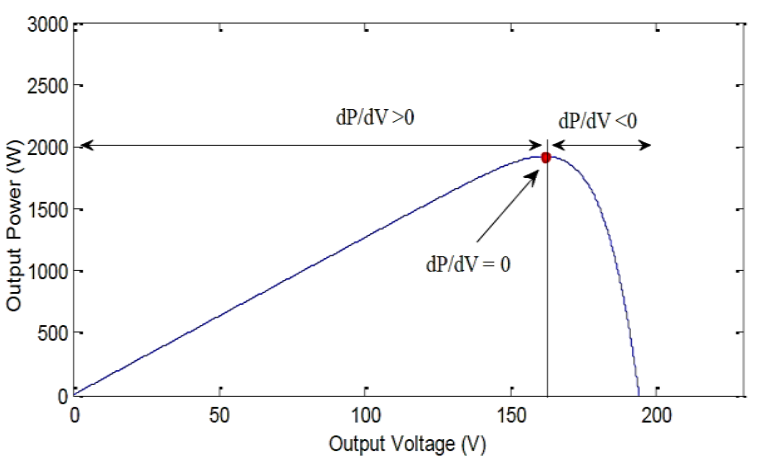

Fig 3: The derivative of power with respect to voltage

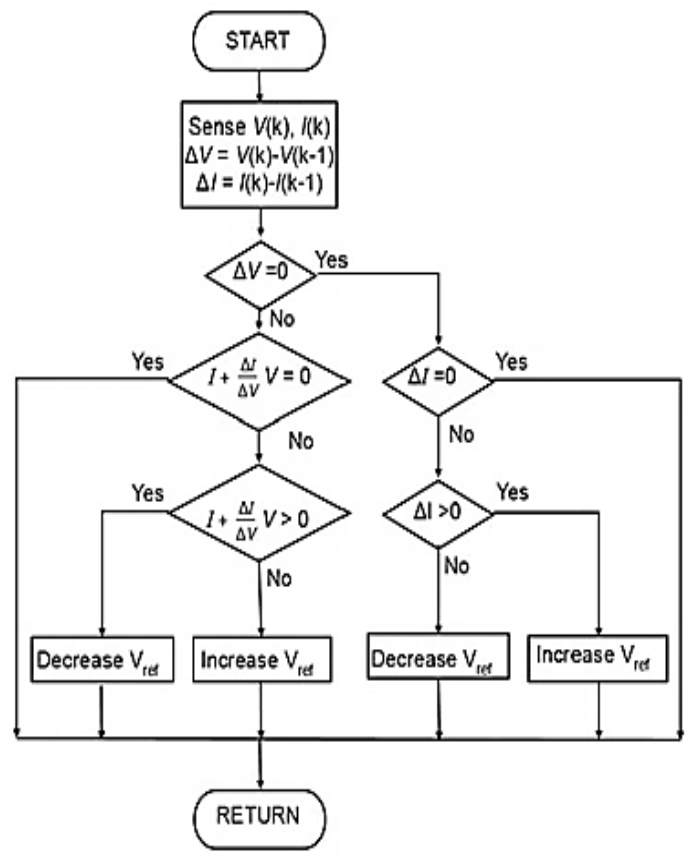

Fig 4: Flowchart of the incremental conductance algorithm.

\section{SIMULATION MODELS AND RESULTS}




\subsection{Boost Converter Model}

The model of a boost converter is given in Ref [12-14]. Figure 5 shows the Matlab/Simulink model for the whole system including PV solar, boost dc converter, MPPT, and BLDC motor with its drive. A 300W PV module has been used in the simulation (Table 1). Two MPPT algorithms are simulated as:

\section{A. Perturb and Observe Simulation Results:}

The PO - MPPT simulation results are discussed. Output voltage for the boost converter with PO - MPPT algorithm is shown in Figure 6, when the irradiance is $1000 \mathrm{~W} / \mathrm{m}^{2}$.

B. Increment Conductance Simulation Results :

Figure 7 shows the output voltage for the boost converter with increment conductance IC - MPPT algorithm. Notice how this looks essentially the same as the voltage plots in Figure 2. The main difference is that the IC algorithm locks onto a specific setting at the maximum power point. Thus, the input and output currents stop fluctuating so much. The duty cycle rises to acquire the MPP for PO-MPPT and IC-MPPT as shown in Figures 9 and 10. Figure 11 shows the comparative results of $\mathrm{PO}$ and IC-MPPT.

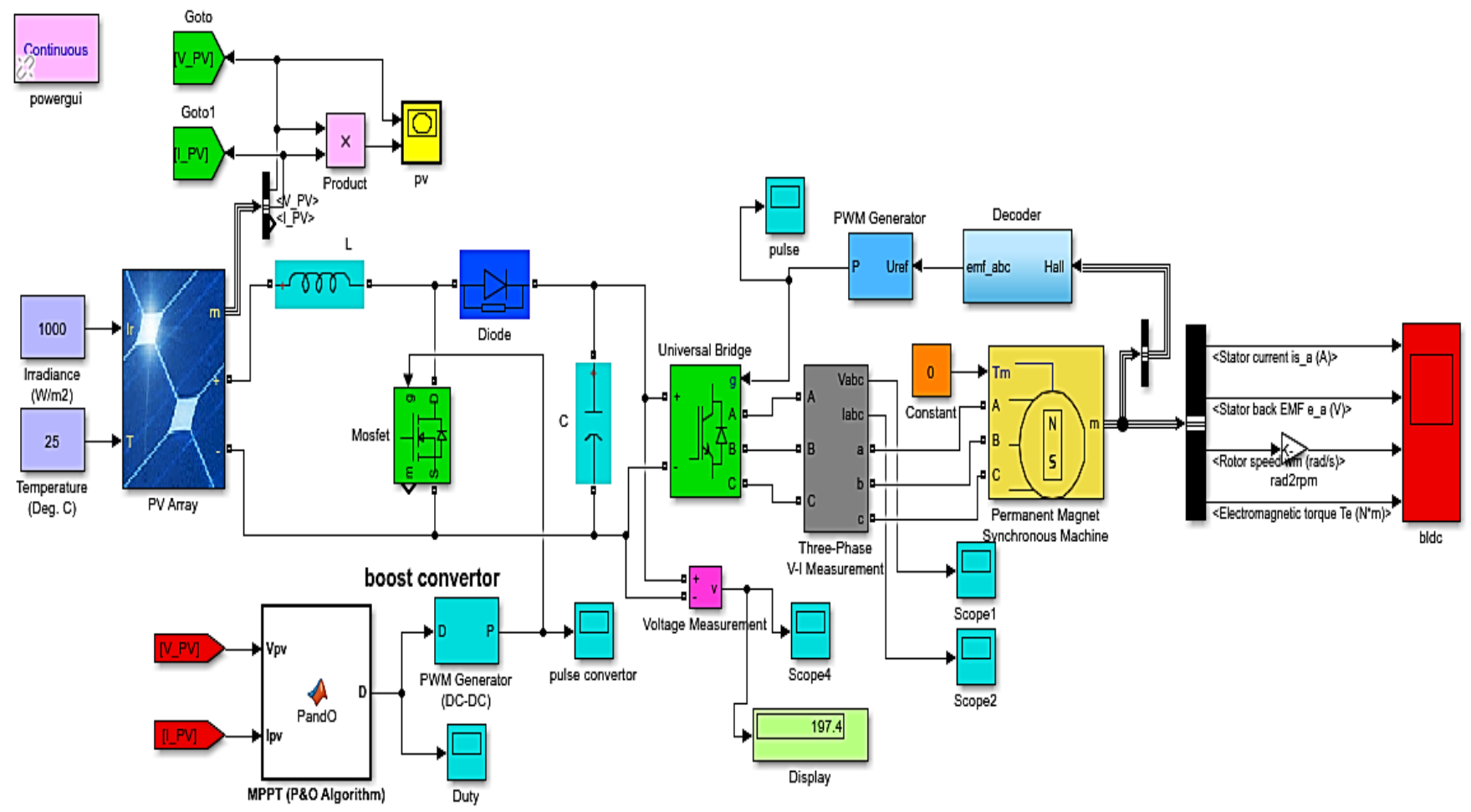

Fig 5 : Matlab/Simulink Model of the whole system

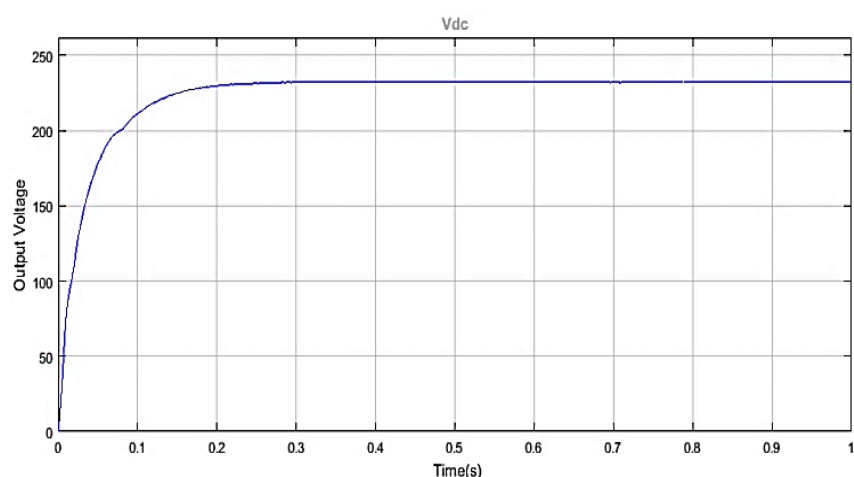

Fig 6 :Output voltage for the boost converter with PO -

MPPT algorithm

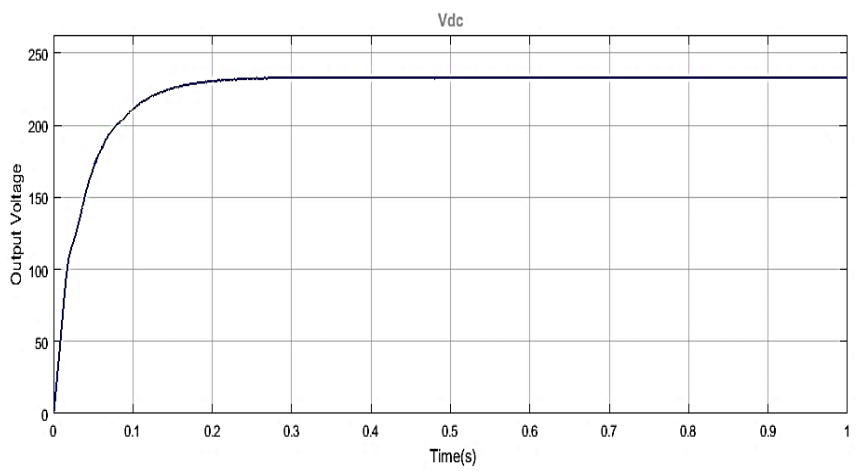

Fig 7 :Output voltage for the boost converter with increment conductance MPPT algorithm

From Figs 6 and 7, it can be observed that the output voltage reaches its rated within $0.2 \mathrm{sec}$ for $\mathrm{P} \& \mathrm{O}$ algorithm and reaches its rated within $0.15 \mathrm{sec}$ for IC algorithm that it is quit 
faster therefore IC under different irradiance conditions has higher accuracy. In other hand, IC is quit complex compared with $\mathrm{P} \& \mathrm{O}$ algorithm.

The performance of SPV boost converter is shown in Fig 8 . The results show the current output, voltage output, PV power when the irradiance is $1000 \mathrm{~W} / \mathrm{m}^{2}$.
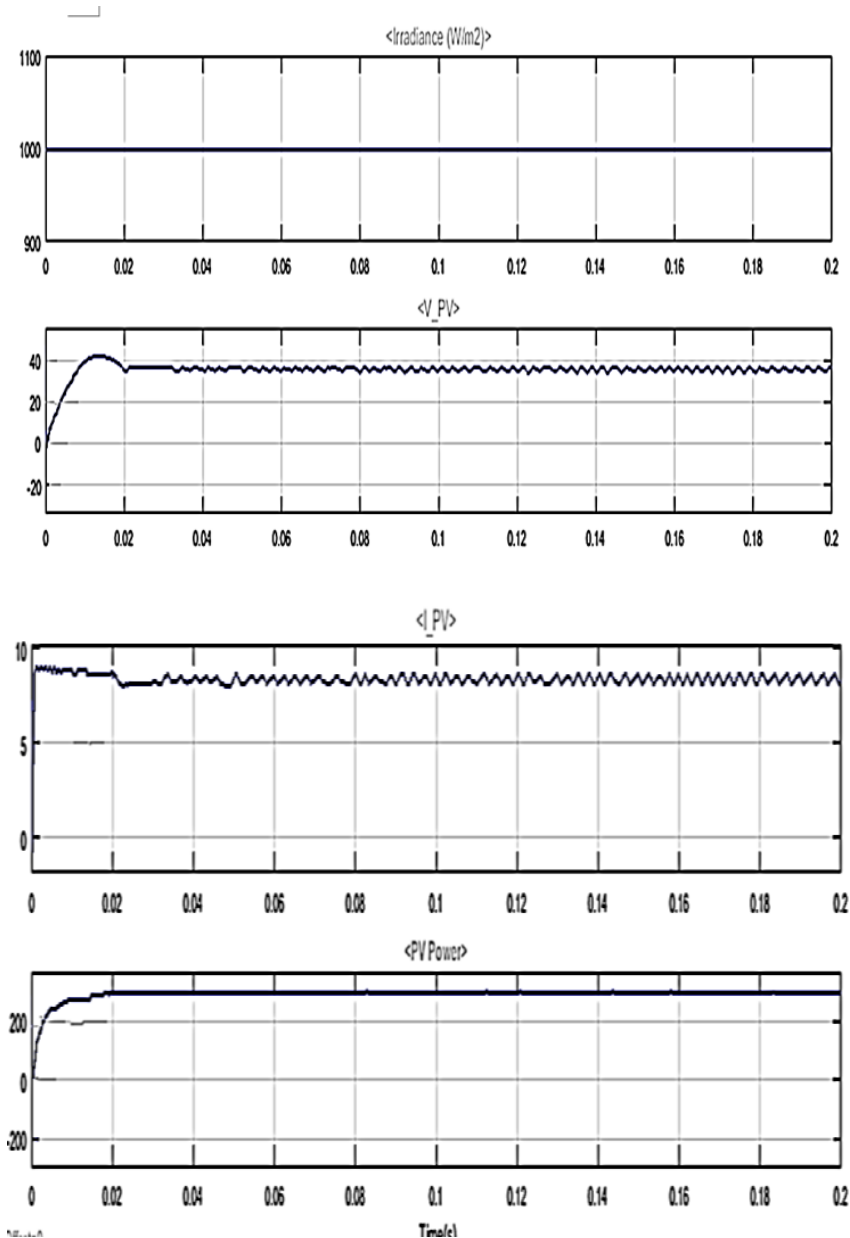

Fig.8 Performance of SPV-boost converter

The simulation results of $\mathrm{P} \& \mathrm{O}$ MPPT algorithm for the duty cycle shown in Fig. 9. The result illustrates that the duty cycle changes for a time period of $0.01 \mathrm{sec}$ and the duty cycle takes $0.005 \mathrm{sec}$ for IC MPPT as shown in Fig. 10.

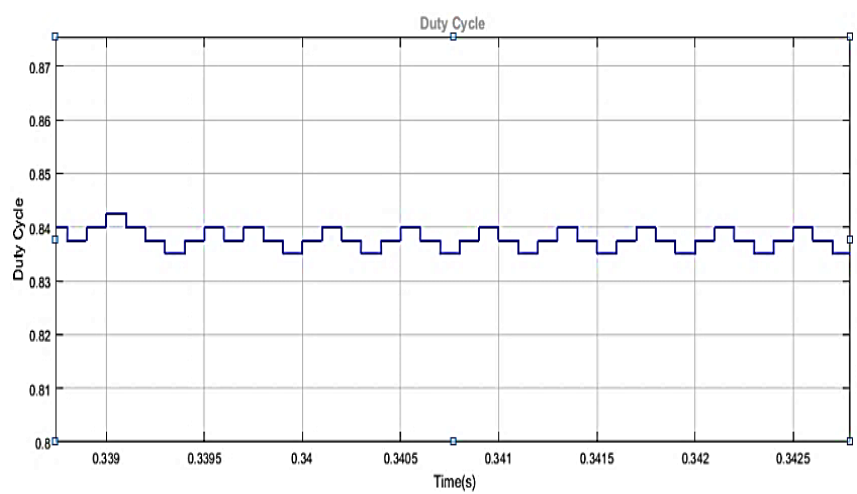

Fig.9 Duty cycle using PO - MPPT Algorithm

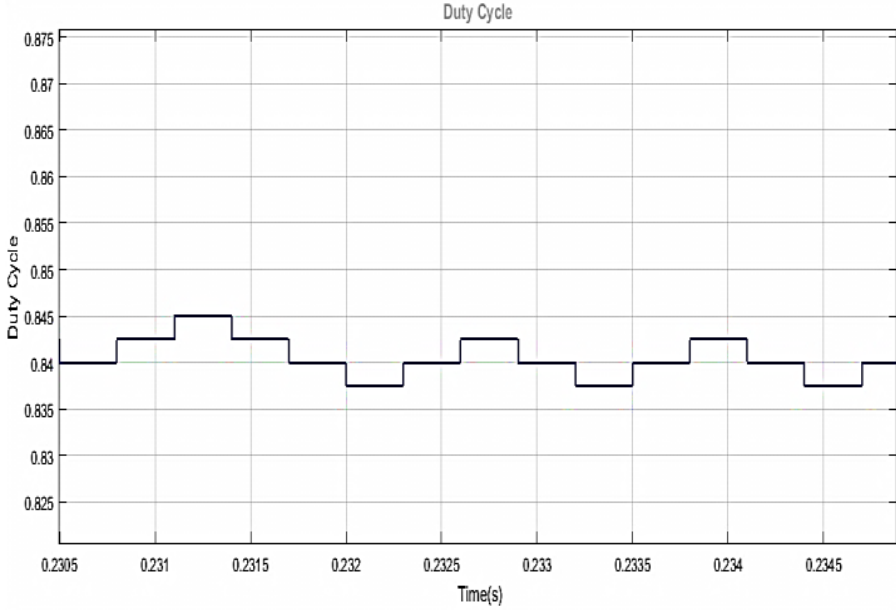

The PV curves are shown in Figs 11, 12 and 13 that display the performance for PV without MPPT and compared when using the MPPT algorithms. It is cleared that tracking for maximum power point for IC MPPT is better than that for PO MPPT due to fast response. Consequently, the comparative between the two algorithms PO and IC maximum power point tracking is given in Table 2 .

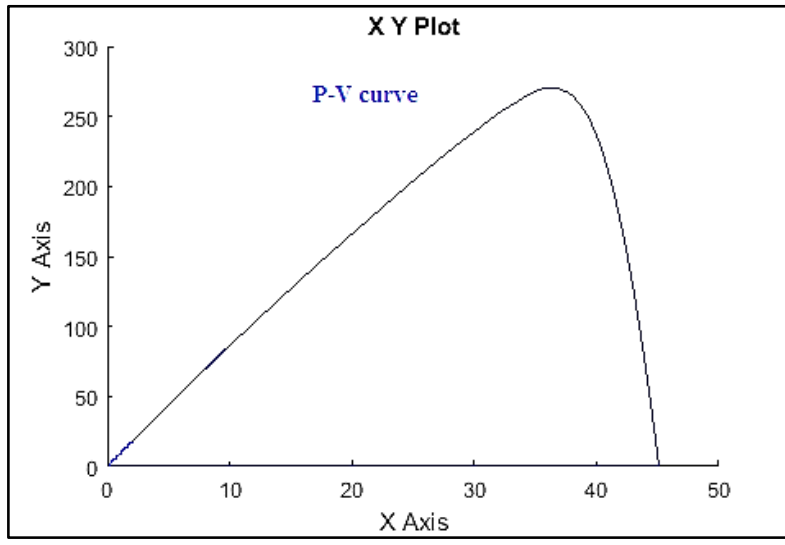

Fig.11 P-V curves Without MPPT

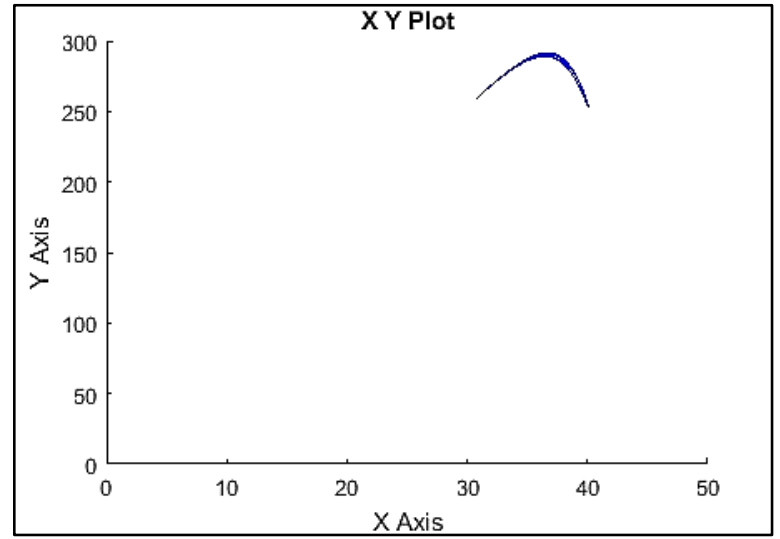

Fig.12 P-V curves PO MPPT 


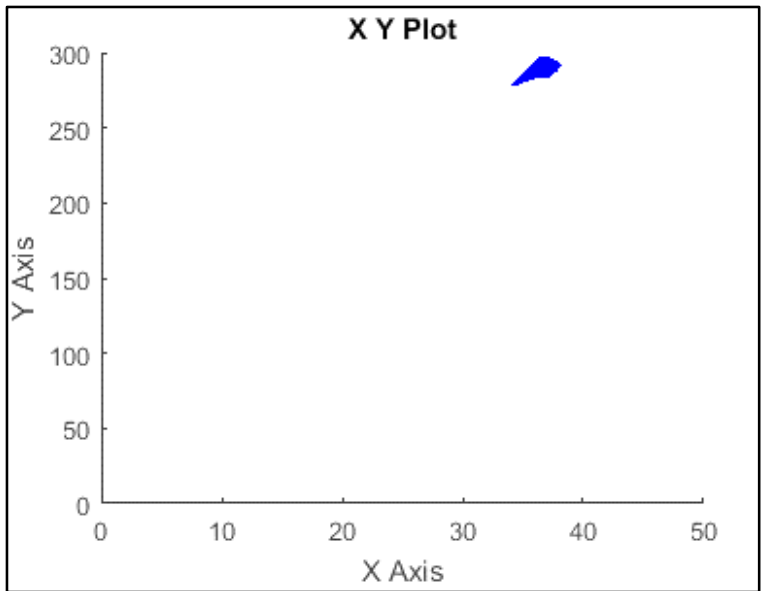

Fig.13 P-V curves IC MPPT

Table 2 Comparative of MPPT simulation results of PO MPPT and IC MPPT

\begin{tabular}{|c|c|c|c|c|c|c|c|c|}
\hline & $\begin{array}{c}\mathrm{P}_{\mathrm{MPP}} \\
(\mathrm{W})\end{array}$ & $\begin{array}{c}\mathrm{P}_{\mathrm{PV}} \\
(\mathrm{W})\end{array}$ & $\begin{array}{c}\mathrm{V}_{\mathrm{MPP}} \\
(\mathrm{V})\end{array}$ & $\begin{array}{c}\mathrm{I}_{\mathrm{MPP}} \\
(\mathrm{A})\end{array}$ & $\begin{array}{c}\mathrm{V}_{\mathrm{dc}} \\
(\mathrm{V})\end{array}$ & $\begin{array}{c}\mathrm{G} \\
\left(\mathrm{W} / \mathrm{m}^{2}\right)\end{array}$ & $\begin{array}{c}\mathrm{T} \\
(\text { Deg. C) }\end{array}$ & $\begin{array}{c}\eta \\
(\%)\end{array}$ \\
\hline P\&O & 296 & 300 & 37.5 & 7.88 & 232 & 1000 & 25 & 98.6 \\
\hline INC & 298 & 300 & 36.85 & 8.1 & 234 & 1000 & 25 & 99.3 \\
\hline P\&O & 236 & 244 & 37.7 & 6.031 & 208 & 800 & 25 & 96.7 \\
\hline INC & 237.5 & 244 & 38.83 & 6 & 208.8 & 800 & 25 & 97.3 \\
\hline P\&O & 185.3 & 190 & 37.9 & 4.8 & 180 & 600 & 25 & 97.6 \\
\hline INC & 186 & 190 & 37.8 & 4.81 & 180.3 & 600 & 25 & 97.9 \\
\hline P\&O & 125 & 132 & 38.03 & 3.2 & 145 & 400 & 25 & 94.7 \\
\hline INC & 128 & 132 & 37.7 & 3.4 & 147 & 400 & 25 & 97 \\
\hline P\&O & 70 & 76 & 37.9 & 1.6 & 100.2 & 200 & 25 & 92 \\
\hline INC & 73 & 76 & 37.6 & 1.8 & 101 & 200 & 25 & 96 \\
\hline
\end{tabular}

In addition, the tracking efficiency for PO and IC MPPT is illustrated in Fig. 14. This figure shows that the variations of irradiance on the tracking efficiency for IC is higher than that for PO. Therefore, the PV array will operate at voltages lower than without MPP voltage, results in increasing the energy utilization efficiency of the system. At lower values of irradiance $200 \mathrm{~W} / \mathrm{m} 2$ the efficiencies are $92 \%$ for PO MPPT and $96 \%$ for IC MPPT

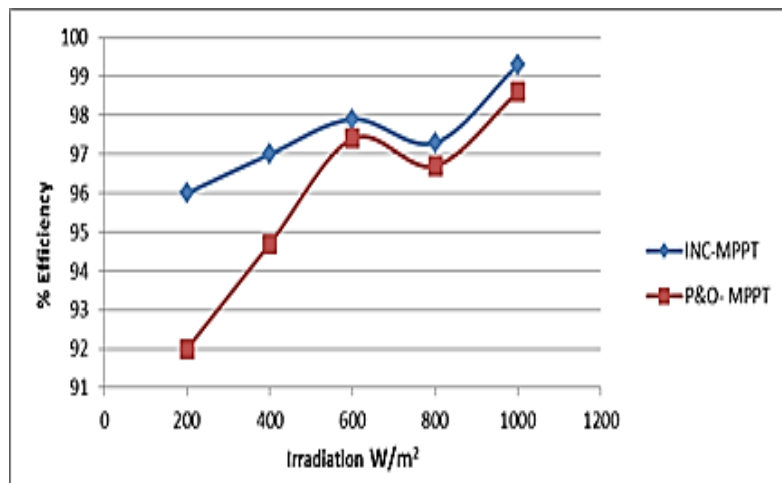

Fig.14 Tracking efficiency: comparison of the proposed INC with the $\mathrm{P} \& \mathrm{O}$ algorithm

\section{CONCLUSIONS}

The solar PV system is simulated so that the performance may be predicted. Two maximum power point tracking algorithms are implemented in order to track the maximum power point of a solar panel. It was observed that the presence oscillates around the MPP using $\mathrm{P} \& \mathrm{O})$. A comprehensive comparative between PO MPPT and IC MPPT are obtained and discussed. So it will use the incremental conductance (INC) algorithm because doesn't oscillate as much as $\mathrm{P} \& \mathrm{O}$ toward the MPP and intending to solve the problem of the $\mathrm{P} \& \mathrm{O}$ algorithm. The system is designed, modeled and its performance is analyzed in MATLAB/Simulink. The various starting, steady state and dynamic behaviors are evaluated, considering the practical operating conditions, which manifests its suitability for water pump.

\section{REFERENCES}

[1] Issam Houssamo, Fabrice Locment and Manuela Sechilariu.2013,"Experimental Analysis of Impact of MPPT Methods on Energy Efficiency for Photovoltaic Power Systems," International Journal of Electrical Power \& Energy Systems, vol. 46, pp. 98-107.

[2] T. K. Soon and S. Mekhilef, , 2014 "Modified Incremental Conductance MPPT Algorithm to Mitigate Inaccurate Responses Under Fast-Changing Solar Irradiation Level," Solar Energy, vol. 101, pp. 333-342.

[3] Kok Soon Tey and S. Mekhilef, 2014 "Modified Incremental Conductance Algorithm for Photovoltaic System under Partial Shading Conditions and Load Variation," IEEE Trans. Ind. Electron., vol.61, no.10, pp.5384-5392.

[4] B. Subudhi and R. Pradhan, 2013 "A Comparative Study on Maximum Power Point Tracking Techniques for Photovoltaic Power Systems," IEEE Transactions on Sustainable Energy, vol. 4, no. 1, pp. 89-98. .

[5] Tey Kok Soon and S. Mekhilef, 2015 "A FastConverging MPPT Technique for Photovoltaic System Under Fast-Varying Solar Irradiation and Load Resistance," IEEE Trans. Ind. Informat., vol.11, no.1, pp.176-18 6.

[6] Chighali Ould Ehssein, Abdellahi Ba1, Ne Ould, Dah, Mamadou Ibrahima Lam and Diakité Amadou1, Aroudam El Hassan, 2018 "Monitoring a maximum power point tracking photovoltaic pumping system", The 9th International Renewable Energy Congress (IREC).

[7] Chavaree Thueanpangthaim; Patumporn Wongyai; Kongpan Areerak; Kongpol Areerak, 2017” The maximum power point tracking for stand-alone photovoltaic system using current based approach,“ International Electrical Engineering Congress (iEECON), Pattaya, Thailand.

[8] S. Sheik Mohammed; D. Devaraj; T. P. Imthias Ahamed, 2016" Maximum power point tracking system for standalone solar PV power system using Adaptive Neuro-Fuzzy Inference System," Biennial International Conference on Power and Energy Systems: Towards Sustainable Energy (PESTSE), Pages: $1-4$.

[9] N. Pongratananukul and T. Kasparis, 2004 "Tool for Automated Simulation of Solar Arrays Using General Purpose Simulators," IEEE Conference Proceedings, 1014.

[10] Akhil Nigam; Abhishek Kumar Gupta. 2016,"Performance and simulation between conventional and improved perturb \&amp; observe MPPT algorithm for solar PV cell using MATLAB/Simulink,” 2016 
International Journal of Computer Applications (0975 - 8887)

Volume 181 - No. 21, October 2018

International Conference on Control, Computing, Communication and Materials (ICCCCM), Pages: $1-4$.

[11] N. Femia ; G. Petrone ; G. Spagnuolo ; M. Vitelli.2005," Optimization of perturb and observe maximum power point tracking method," IEEE Transactions on Power Electronics, , Volume: 20, Issue: 4, Pages: 963 - 973.

[12] Ned Mohan, Tore M. Undeland and William P. Robbins, 2000.Power Electronics: Converters, Applications and
Design, 3rd Ed. New Delhi, India: John Wiley \& sons Inc.,

[13] K.I.Hwu; Y.T.Yau.2010,”A KY Boost Converter,” IEEE Transactions on Power Electronics, Volume: 25, Issue: 11, pages: $2699-2703$.

[14] P. Midya ; K. Haddad ; M. Miller, 2004”Buck or boost tracking power converter, "IEEE Power Electronics Letters, Volume: 2, Issue: 4,pages: $131-134$. 